\title{
GERENCIAMENTO ENERGÉTICO NO SISTEMA DE SANEAMENTO BÁSICO DO MUNICÍPIO DE JAGUARIÚNA: UMA ABORDAGEM LEGAL E PRÁTICA
}

Energy management in the basic sanitation system of the municipality of Jaguariúna:

A legal and practical approach

http://dx.doi.org/10.21116/2017.3

SOUZA, Luciana Carla Ferreira de

Faculdade de Jaguariúna - FAJ

Prefeitura do Município de Jaguariúna

DORTA, Lucas Henrique Rodrigues

Prefeitura do Município de Jaguariúna

Pontifícia Universidade Católica de Campinas - PUC-CAMPINAS

Resumo: O gerenciamento energético de instalações elétricas é composto de medidas de diagnóstico, prognóstico e atuação nos índices cujo objetivo é a adequação da mesma, visando sua regularização, o que traz consequentes economias financeiras uma vez que a irregularidade energética gera multas e maiores valores a serem pagos. Esta gestão pode começar analisando as contas de energia elétrica, pois apresentam várias variáveis, como consumo e demanda, que obedecem a normas de utilização que limitam certos parâmetros energéticos e, sua regularidade ou não, interfere diretamente em seu valor financeiro. Assim, o presente trabalho objetiva comprovar a rentabilidade de medidas simples de gerenciamento energético no sistema de saneamento básico do município de Jaguariúna, procedendo desde o levantamento dos dados até a atuação nos índices. Evidenciando que os resultados obtidos mostraram o grande potencial de tal gestão, uma vez que não se necessitou de investimentos. Portanto, conclui-se que o gerenciamento energético de um sistema de saneamento trará economias reais em curto prazo, sendo apenas necessárias ações burocráticas de regularização.

Palavras-chave: gerenciamento energético; regularização; eficiência energética.

Abstract: The energy management of electrical installations is composed of diagnostic, prognostic and actuation measures in the indices whose objective is the adequacy of the same, aiming at their regularization, which brings with it financial savings, since the energy irregularity generates fines and higher values to be paid . This management can start by analyzing electric energy accounts, since they present several variables, such as consumption and demand, that obey rules of use that limit certain energy parameters, whether or not they directly interfere in their financial value. Thus, the present work aims to prove the profitability of simple measures of energy management in the basic sanitation system of the municipality of Jaguariúna, proceeding from the data collection to the performance in the indices. Evidence that the results obtained showed the great potential of such management, since it did not require investments. Therefore, it is concluded that the energetic management of a sanitation system will bring real savings in the short term, being only necessary bureaucratic regularization actions.

Keywords: energy management; regularization; energy efficiency. 


\section{INTRODUÇÃO}

A crise energética, que teve seu pico em 2001, quando em julho, iniciou-se o primeiro racionamento em escala nacional, obrigou a sociedade brasileira a mudar seus hábitos e reduzir o consumo de energia elétrica (SCHIMIDT, 2004).

Desde então medidas vem sendo tomadas neste aspecto, o governo, por exemplo, optou por utilizar empresas estatais para executar programas nacionais de conservação de energia, como a Eletrobrás (SOUZA et al, 2009), sendo um dos programas gerenciados por esta estatal o Programa Nacional de Conservação de Energia Elétrica (Procel) que promove o uso eficiente da energia elétrica, combatendo o desperdício, reduzindo os custos e os investimentos setoriais (ELETROBRÁS, 2016).

Além disso, outro órgão importante é a Agência Nacional de Energia Elétrica (ANEEL) que tem como finalidade a regularização do setor elétrico brasileiro, e estabelece, por meio de resoluções normativas, condições gerais sobre produção, transmissão, distribuição e comercialização de energia elétrica (BRASIL, 1996). Suas resoluções normativas impõem enquadramentos e limites energéticos, como a Resolução Normativa $n^{\circ} 414$, de 9 de setembro de 2010, que estabelece as condições gerais de fornecimento de energia elétrica de forma atualizada e consolidada, cujas disposições devem ser observadas pelas distribuidoras e consumidores.

Nesta resolução há conceitos importantes que devem ser destacados se se deseja fazer um coeso gerenciamento energético. Preliminarmente, é necessário saber que as instalações elétricas são divididas em dois grupos de acordo com a tensão de fornecimento: o grupamento com tensão de fornecimento igual ou superior a 2,3kV é nomeado de grupo A e o grupamento com tensão de fornecimento inferior a 2,3kV é nomeado grupo B (salvo exceções); cada grupo apresenta modalidades tarifárias diferentes, sendo convencional monômia e horária branca, modalidades do grupo B e, convencional binômia, horária verde e horária azul, modalidades do grupo A; a diferença entre as tarifas convencionais e horárias, é a independência ou não das horas de utilização do dia, enquanto que para as convencionais são tarifas independente das horas de utilização do dia, para as horárias há essa dependência (ANEEL, 2010). 
O grupo A apresenta como fluxo de energia, além do consumo, demanda, que segundo ANEEL (2000) é "a média das potências elétricas ativas ou reativas, solicitado ao sistema elétrico pela parcela de carga instalada em operação na unidade consumidora, durante um intervalo de tempo especificado", e este fluxo deve ser firmado em contrato entre o solicitante e a distribuidora.

Deve-se destacar, no entanto, que de acordo com a ampliação ou redução da unidade consumidora a demanda pode crescer ou diminuir, assim, uma análise de demanda diagnosticará as reais necessidades da instalação e preverá ações que visem adequá-la, uma vez que um superdimensionamento acarretará num valor pago por kWh maior do que o realmente necessário, e um sub-dimensionamento acarretará em multas por ultrapassagem de demanda, conforme art. 93, da Resolução Normativa $n^{\circ}$ 414, de 09 de setembro de 2010, da ANEEL, que diz:

"Quando os montantes de demanda de potência ativa ou de uso do sistema de distribuição - MUSD medidos excederem em mais de $5 \%$ (cinco por cento) os valores contratados deve ser adicionada ao faturamento regular a cobrança pela ultrapassagem (ANEEL, 2010)."

Dessa forma, deve-se haver um constante acompanhamento desse fluxo, para que se possa escolher a melhor opção na renovação periódica do contrato de demanda.

Além disso, as instalações são divididas em classes, de acordo com a atividade nela exercida e a finalidade da utilização da energia elétrica, existem sete classes possíveis a uma instalação, a saber, classe residencial, industrial, comercial, rural, poder público, iluminação pública e serviço público (ANEEL, 2010).

As instalações de pessoa jurídica de direito público podem ser classificadas como poder público, iluminação pública ou serviço público; vale ressaltar quais instalações se enquadram na classe serviço público, de acordo com o art. $5, \S 7^{\circ}$, da Resolução Normativa $n^{\circ}$ 414, de 09 de setembro de 2010, da ANEEL:

"A classe serviço público caracteriza-se pelo fornecimento exclusivo para motores, máquinas e cargas essenciais à operação de serviços públicos de água, esgoto, saneamento e tração elétrica urbana ou ferroviária, explorados diretamente pelo Poder Público ou mediante concessão ou autorização, considerando-se as seguintes subclasses: I - tração elétrica; e II - água, esgoto e saneamento (ANEEL, 2010)." 
Levando este parágrafo em consideração e o Decreto $n^{\circ} 7.891$, de 23 de janeiro de 2013, da Casa Civil, o qual regulamenta a Lei $n^{\circ} 12.783$, de 11 de janeiro de 2013, que dispõe sobre as concessões de geração, transmissão e distribuição de energia elétrica, sobre a redução dos encargos setoriais e sobre a modicidade tarifária, art. 1, inciso IV, que informa: "redução na tarifa de uso do sistema de distribuição e na tarifa de energia aplicável à unidade consumidora classificada como de serviço público de água, esgoto e saneamento, nos termos deste Decreto", percebe-se que há descontos para o serviço de saneamento básico, o qual segundo CPFL (2016) é um desconto de 15\% sobre as tarifas aplicadas para consumo e demanda de potência para classe serviço público.

A partir destes conceitos básicos é possível aplicar um coerente gerenciamento energético que segundo Marques, Haddad e Guardia (2007), devese começar conhecendo as informações relacionadas com os fluxos de energia, levando em consideração as ações que o influenciam, e os processos e atividades que utilizam a energia e relacionam com um produto ou serviço; seguido de um acompanhamento dos índices de controle de consumo e utilização; e por fim, a atuação nos índices, com ações que busquem reduzir o consumo energético.

Um ponto importante é que as principais informações relacionadas aos fluxos de energia podem ser extraídas da conta de energia elétrica, possibilitando um diagnóstico de como está sendo utilizada a energia, sendo, dessa forma, possível, uma avaliação, qual busque ações que visem regularizar a situação, se a mesma não estiver em regularidade.

Assim, o objetivo deste artigo é fazer um levantamento dos índices de controle de consumo e utilização da energia elétrica, e realizar um prognóstico, a fim de encontrar fluxos de energia fora de regularidade para realizar ações que visem sua regularização.

\section{METODOLOGIA}

O desenvolvimento do estudo ocorreu na Secretaria de Meio Ambiente da Prefeitura Municipal de Jaguariúna, responsável pelo saneamento básico; inicialmente realizou-se um levantamento preliminar das contas de energia elétrica de um ano de cada uma de suas instalações, separando-as de acordo com seu grupamento. 
Nas contas do grupo A, efetuou-se análise energética e financeira, tabelando todos os fluxos presentes nas contas mensais de energia elétrica, conforme consta no Apêndice A, a fim de se obter o comportamento de cada instalação.

Com o diagnóstico realizado, avaliou-se os resultados a fim de se obter padrões de irregularidade, encontrando-os se tomou as medidas possíveis a sua regularização.

Com propósito de quantificar a economia gerada com as ações realizadas criou-se tabelas comparativas de quanto se pagaria na irregularidade, utilizando para tarifa de cobrança por ultrapassagem uma média anual de cada instalação, e quanto pagou-se na regularidade.

Nas contas do grupo $B$, efetuou-se uma análise energética e financeira, tabelando o consumo energético e o valor pago presentes nas contas mensais de energia elétrica, para obter índice preço médio, conforme consta no Apêndice $B$, com interesse em comparar os preços médios de cada instalação.

Finalizado o diagnóstico, analisou-se os resultados e realizou-se medidas para regularização de instalações que estavam fora da regularidade.

\section{RESULTADOS E DISCUSSÃO}

A secretaria apresenta seis instalações de alta tensão (grupo A) que possuem consumos e demandas, típicos, de acordo com a potência instalada em cada uma delas. No apêndice $A$, em que consta o levantamento do comportamento de cada instalação, percebeu-se que existiam três instalações que ultrapassavam certos limites estabelecidos em contrato e que, portanto, estavam fora da regularidade, e por tal condição pagavam multas onerosas.

A irregularidade estava na demanda contratada, uma vez que o valor firmado em contrato estava sendo ultrapassado, e as multas eram decorrentes dessas ultrapassagens. Os procedimentos para mitigar ou eliminar estas ultrapassagens são: aumento de demanda contratada ou redução da potência instalada. Como não é possível reduzir a potência instalada, tendo em vista serem serviços essenciais ao saneamento, aumentou-se a demanda dessas instalações.

Outro aspecto foi que uma das instalações estava numa modalidade tarifária que era desvantajosa, haja vista o alto valor pago pelo consumo uma vez que não 
se tinha demanda contratada, então, trocou-se a modalidade tarifária. As mudanças realizadas em cada instalação foram:

- Captação Jaguari: Aumento da demanda contratada de $360 \mathrm{~kW}$ para $400 \mathrm{~kW}$ nos horários de ponta e fora de ponta, ou seja, um aumento de $11,1 \%$.

- Estação Elevatória de Esgoto 9: Aumento da demanda contratada de $30 \mathrm{~kW}$ para $129 \mathrm{~kW}$, ou seja, um aumento de 330,0\%. Troca da modalidade tarifária de convencional binômia para horária verde.

- Estação de Tratamento de Esgoto Camanducaia: Aumento da demanda contratada de $160 \mathrm{~kW}$ para $210 \mathrm{~kW}$, ou seja, um aumento de $31,3 \%$.

Com este diagnóstico pode-se quantificar o quanto se pagou por estarem fora da regularidade, em um ano as multas foram: $R \$ 14.327,08$ na Captação Jaguari; $R$ \$ 31.235,46 na Estação Elevatória de Esgoto 9; e $R \$ 19.704,03$ na Estação de Tratamento de Esgoto Camanducaia. Logo, somam um total anual de $\mathrm{R} \$ 65.266,57$.

A medida para eliminar estas multas não necessitou de nenhum investimento e, além disso, se apresentou eficiente, uma vez que eliminou as multas por ultrapassagem, salvo alguns meses atípicos.

As Tabelas 01 a 03 apresentam uma projeção de quanto se pagaria de multas se não houvesse adequação e quanto realmente se pagou, segundo a Tabela 01 pagar-se-ia na Captação Jaguari, se não houvesse adequação de demanda, um semestral de $\mathrm{R} \$ 11.981,32$ de multas de ultrapassagem, contudo com a adequação que se realizou, pagou-se um semestral de $R \$ 1.094,67$ de multas de ultrapassagem, de acordo com a Tabela 02 pagar-se-ia na Estação Elevatória de Esgoto 9, se não houvesse adequação de demanda, um semestral de $\mathrm{R} \$ 18.748,96$ de multas de ultrapassagem, contudo com a adequação que foi realizada, pagou-se um semestral de $\mathrm{R} \$ 416,46$ de multas de ultrapassagem, e segundo Tabela 03 pagar-se-ia na Estação de Tratamento de Esgoto Camanducaia, se não houvesse adequação de demanda, um semestral de $\mathrm{R} \$ 10.268,02$ de multas de ultrapassagem, contudo com a adequação que se realizou, não se pagou nada de multas de ultrapassagem.

Assim, se não houvesse as adequações de demanda contratada, pagar-seia um semestral de $\mathrm{R} \$ 40.998,30$ de multas por ultrapassagem, contudo com as mudanças de demanda contratada pagou-se, efetivamente, um semestral de 
$\mathrm{R} \$ 1.511,13$. Logo, a economia gerada com a adequação da demanda contratada, levando em consideração que não houve necessidade de nenhum investimento, foi um semestral de $\mathrm{R} \$ 39.487,17$.

Tabela 01 - Comparação energética e financeira das multas de ultrapassagem de demanda, sem e com as adequações realizadas na instalação da Captação Jaguari.

\begin{tabular}{|c|c|c|c|c|c|c|c|c|c|}
\hline \multicolumn{10}{|c|}{ ANÁLISE ENERGÉTICA - SEM MUDANÇA DE DEMANDA } \\
\hline \multirow[b]{2}{*}{ MÊS } & \multicolumn{3}{|c|}{ HORÁRIO DE PONTA } & \multicolumn{3}{|c|}{ HORÁRIO FORA DE PONTA } & & & \multirow[b]{2}{*}{$\begin{array}{l}\text { VALOR DA } \\
\text { MULTA (R\$) }\end{array}$} \\
\hline & \begin{tabular}{|l|} 
DEMANDA \\
ATIVA (kW) \\
FATURADO
\end{tabular} & $\begin{array}{c}\text { DEMANDA } \\
\text { CONTRATADA } \\
\end{array}$ & $\begin{array}{l}\text { ULTRAPASSAGEM } \\
(\mathrm{kW})\end{array}$ & $\begin{array}{l}\text { DEMANDA } \\
\text { ATIVA (kW) } \\
\text { FATURADO }\end{array}$ & $\begin{array}{c}\text { DEMANDA } \\
\text { CONTRATADA } \\
\end{array}$ & $\begin{array}{c}\text { ULTRAPASSAGEM } \\
(\mathrm{kW})\end{array}$ & \multicolumn{2}{|c|}{$\begin{array}{l}\text { TARIFA DA COBRANCCA POR } \\
\text { ULTRAPASSAGEM (R\$) }\end{array}$} & \\
\hline mar-16 & 423 & 360 & 63 & 445 & 360 & 85 & 35,98 & 12,52 & $3.330,94$ \\
\hline abr-16 & 408 & 360 & 48 & 442 & 360 & 82 & 35,98 & 12,52 & $2.753,68$ \\
\hline mai-16 & 402 & 360 & 42 & 405 & 360 & 45 & 35,98 & 12,52 & $2.074,56$ \\
\hline jun-16 & 403 & 360 & 43 & 408 & 360 & 48 & 35,98 & 12,52 & $2.148,10$ \\
\hline jul-16 & 394 & 360 & 34 & 396 & 360 & 36 & 35,98 & 12,52 & $1.674,04$ \\
\hline ago-16 & 375 & 360 & 0 & 375 & 360 & 0 & 35,98 & 12,52 & 0,00 \\
\hline SOMAS & & & & & & & & & $11.981,32$ \\
\hline
\end{tabular}

OBS: Valores de ultrapassagem menores que $5 \%$ não foram considerados.

\begin{tabular}{|c|c|c|c|c|c|c|c|c|c|}
\hline \multicolumn{10}{|c|}{ ANÁLISE ENERGÉTICA - COM MUDANÇA DE DEMANDA } \\
\hline \multirow[b]{2}{*}{ MÊS } & \multicolumn{3}{|c|}{ HORÁRIO DE PONTA } & \multicolumn{3}{|c|}{ HORÁRIO FORA DE PONTA } & & & \multirow[b]{2}{*}{$\begin{array}{l}\text { VALOR DA } \\
\text { MULTA (R\$) }\end{array}$} \\
\hline & \begin{tabular}{|l|} 
DEMANDA \\
ATIVA (kW) \\
FATURADO
\end{tabular} & $\begin{array}{c}\text { DEMANDA } \\
\text { CONTRATADA } \\
(\mathrm{kW})\end{array}$ & $\begin{array}{c}\text { ULTRAPASSAGEM } \\
(\mathrm{kW})\end{array}$ & $\begin{array}{l}\text { DEMANDA } \\
\text { ATIVA (kW) } \\
\text { FATURADO }\end{array}$ & $\begin{array}{c}\text { DEMANDA } \\
\text { CONTRATADA } \\
(\mathrm{kW})\end{array}$ & $\begin{array}{c}\text { ULTRAPASSAGEM } \\
(\mathrm{kW})\end{array}$ & \multicolumn{2}{|c|}{$\begin{array}{l}\text { TARIFA DA COBRANÇA POR } \\
\text { ULTRAPASSAGEM (R\$) }\end{array}$} & \\
\hline mar-16 & 423 & 400 & 23 & 445 & 400 & 45 & - & 12,55 & 564,63 \\
\hline$a b r-16$ & 408 & 400 & 0 & 442 & 400 & 42 & - & 12,62 & 530,04 \\
\hline mai-16 & 402 & 400 & 0 & 405 & 400 & 0 & - & - & 0,00 \\
\hline jun-16 & 403 & 400 & 0 & 408 & 400 & 0 & - & - & 0,00 \\
\hline jul-16 & 394 & 400 & 0 & 396 & 400 & 0 & - & - & 0,00 \\
\hline ago-16 & 375 & 400 & 0 & 375 & 400 & 0 & - & - & 0,00 \\
\hline SOMAS & & & & & & & & & $1.094,67$ \\
\hline
\end{tabular}

OBS: Valores de ultrapassagem menores que $5 \%$ não foram considerados.

Em Março a ultrapassagem fora maior que 5\%, mas a CPFL não cobrou multa por tal ultrapassagem.

Tabela 02 - Comparação energética e financeira das multas de ultrapassagem de demanda, sem e com as adequações realizadas na instalação da Estação Elevatória de Esgoto 9.

\begin{tabular}{|l|c|c|c|c|c|}
\hline \multicolumn{6}{|c|}{ ANÁLISE ENERGÉTICA - SEM MUDANÇA DE DEMANDA } \\
\hline MÊS & $\begin{array}{c}\text { DEMANDA } \\
\text { ATIVA (kW) } \\
\text { FATURADO }\end{array}$ & $\begin{array}{c}\text { DEMANDA } \\
\text { CONTRATADA } \\
(\mathbf{k W})\end{array}$ & $\begin{array}{c}\text { ULTRAPASSAGEM } \\
\mathbf{( k W )}\end{array}$ & $\begin{array}{c}\text { TARIFA DA COBRANÇA } \\
\text { POR ULTRAPASSAGEM } \\
\text { (R\$) }\end{array}$ & $\begin{array}{c}\text { VALOR DA } \\
\text { MULTA (R\$) }\end{array}$ \\
\hline mar-16 & 117 & 30 & 87 & 38,42 & $3.342,54$ \\
\hline abr-16 & 107 & 30 & 77 & 38,42 & $2.958,34$ \\
\hline mai-16 & 162 & 30 & 132 & 38,42 & $5.071,44$ \\
\hline jun-16 & 107 & 30 & 77 & 38,42 & $2.958,34$ \\
\hline jul-16 & 88 & 30 & 58 & 38,42 & $2.228,36$ \\
\hline ago-16 & 87 & 30 & 57 & 38,42 & $2.189,94$ \\
\hline
\end{tabular}

OBS: Valores de ultrapassagem menores que $5 \%$ não foram considerados.

\begin{tabular}{|l|c|c|c|c|c|}
\hline \multicolumn{6}{|c|}{ ANÁLISE ENERGÉTICA - SEM MUDANÇA DE DEMANDA } \\
\hline MÊS & $\begin{array}{c}\text { DEMANDA } \\
\text { ATIVA (kW) } \\
\text { FATURADO }\end{array}$ & $\begin{array}{c}\text { DEMANDA } \\
\text { CONTRATADA } \\
(\mathbf{k W})\end{array}$ & $\begin{array}{c}\text { ULTRAPASSAGEM } \\
(\mathbf{k W )}\end{array}$ & $\begin{array}{c}\text { TARIFA DA COBRANÇA } \\
\text { POR ULTRAPASSAGEM } \\
(\text { R\$) }\end{array}$ & $\begin{array}{c}\text { VALOR DA } \\
\text { MULTA (R\$) }\end{array}$ \\
\hline mar-16 & 117 & 129 & 0 & - & 0,00 \\
\hline abr-16 & 107 & 129 & 0 & - & 0,00 \\
\hline mai-16 & 162 & 129 & 33 & 12,62 & 416,46 \\
\hline jun-16 & 107 & 129 & 0 & - & 0,00 \\
\hline jul-16 & 88 & 129 & 0 & - & 0,00 \\
\hline ago-16 & 87 & 129 & 0 & - & 0,00 \\
\hline
\end{tabular}

OBS: Valores de ultrapassagem menores que $5 \%$ não foram considerados. 
Em relação ao grupo de baixa tensão (grupo B), a secretaria possui 42 instalações. No apêndice $B$, em que consta o levantamento do índice preço médio, percebeu-se que havia instalações que possuíam um preço médio acima dos demais, o que levava a um valor pago maior em relação às outras.

Tabela 03 - Comparação energética e financeira das multas de ultrapassagem de demanda, sem e com as adequações realizadas na instalação da Estação de Tratamento de Esgoto Camanducaia.

\begin{tabular}{|c|c|c|c|c|c|c|c|c|c|}
\hline \multicolumn{10}{|c|}{ ANÁLISE ENERGÉTICA - SEM MUDANÇA DE DEMANDA } \\
\hline MÊS & \multicolumn{3}{|c|}{ HORÁRIO DE PONTA } & \multicolumn{3}{|c|}{ HORÁRIO FORA DE PONTA } & & & $\begin{array}{l}\text { VALOR DA } \\
\text { MULTA (R\$) }\end{array}$ \\
\hline abr-16 & 192 & 160 & 32 & 194 & 160 & 34 & 35,98 & 12,52 & $1.577,04$ \\
\hline mai-16 & 187 & 160 & 27 & 190 & 160 & 30 & 35,98 & 12,52 & $1.347,06$ \\
\hline jun-16 & 190 & 160 & 30 & 192 & 160 & 32 & 35,98 & 12,52 & $1.480,04$ \\
\hline SOMAS & & & & & & & & & $10.268,02$ \\
\hline
\end{tabular}

OBS: Valores de ultrapassagem menores que $5 \%$ não foram considerados.

\begin{tabular}{|c|c|c|c|c|c|c|c|c|c|}
\hline \multicolumn{10}{|c|}{ ANÁLISE ENERGÉTICA - SEM MUDANÇA DE DEMANDA } \\
\hline MÊS & \multicolumn{3}{|c|}{ HORÁRIO DE PONTA } & \multicolumn{3}{|c|}{ HORÁRIO FORA DE PONTA } & & & $\begin{array}{l}\text { VALOR DA } \\
\text { MULTA (R\$) }\end{array}$ \\
\hline abr-16 & 192 & 210 & 0 & 194 & 210 & 0 & - & - & 0,00 \\
\hline mai-16 & 187 & 210 & 0 & 190 & 210 & 0 & - & - & 0,00 \\
\hline jun-16 & 190 & 210 & 0 & 192 & 210 & 0 & - & - & 0,00 \\
\hline SOMAS & & & & & & & & & 0,00 \\
\hline
\end{tabular}

Essa diferença no preço médio nas instalações de baixa tensão era devido à classificação que estavam: poder público; enquanto que todas as demais estavam classificadas como serviço público, e dessa forma, como discutido na introdução, gozavam de um desconto de $15 \%$ sobre as tarifas.

O procedimento para passar a gozar este desconto é a mudança de classificação de poder público para serviço público, nas instalações que se enquadram nesta classe, assim, das cinco instalações, uma não poderá participar do desconto, a saber, o Departamento de Água e Esgoto, uma vez que sua atividade é predominantemente administrativa.

De acordo com a Tabela 04 pagou-se um total anual de $\mathrm{R} \$ 52.623,35$ por um consumo de $94.147 \mathrm{kWh}$ nas quatro instalações, assim o preço médio foi de $0,559 \mathrm{R} \$ / \mathrm{kWh}$. Se estas instalações estivessem usufruindo do desconto da classe de serviço público, o valor total anual por um consumo de $94.147 \mathrm{kWh}$ seria de $\mathrm{R} \$ 44.729,85$, assim um preço médio de 0,475R\$/kWh. Logo, uma economia de $\mathrm{R} \$ 7.893,50$ nas quatro instalações. Ressalta-se que não é necessário nenhum investimento financeiro para se realizar a mudança de classificação. 
Tabela 04 - Levantamento energético e financeiro das instalações em que houve troca de classificação de poder público para serviço público.

\begin{tabular}{|c|c|c|c|c|}
\hline & \multicolumn{4}{|c|}{ ANÁLISE ENERGÉTICA } \\
\hline & 3060010122 & 3060000184 & 4000785238 & 3060001262 \\
\hline set $/ 15$ & 3.281 & 461 & 965 & 2.520 \\
\hline out/15 & 4.152 & 572 & 983 & 2.220 \\
\hline nov/15 & 3.558 & 578 & 1.167 & 1.860 \\
\hline dez/15 & 5.617 & 304 & 1.440 & 1.320 \\
\hline jan/16 & 3.620 & 536 & 1.297 & 1.200 \\
\hline fev/16 & 8.349 & 397 & 1.446 & 1.020 \\
\hline mar/16 & 3.801 & 917 & 1.429 & 1.230 \\
\hline$a b r / 16$ & 5.624 & 1.057 & 1.369 & 1.110 \\
\hline mai/16 & 4.128 & 1.105 & 1.347 & 1.290 \\
\hline jun/16 & 3.665 & 776 & - & 1.290 \\
\hline $\mathrm{jul} / 16$ & 4.303 & 821 & 1.283 & 1.200 \\
\hline ago/16 & 3.903 & 904 & 1.472 & 1.260 \\
\hline SOMAS & 54.001 & 8.428 & 14.198 & 17.520 \\
\hline
\end{tabular}

\begin{tabular}{|c|c|c|c|c|}
\cline { 2 - 5 } \multicolumn{1}{c|}{} & \multicolumn{4}{c|}{ ANÁLISE FINANCEIRA- R\$ } \\
\cline { 2 - 5 } \multicolumn{1}{c|}{} & $\mathbf{3 0 6 0 0 1 0 1 2 2}$ & $\mathbf{3 0 6 0 0 0 0 1 8 4}$ & $\mathbf{4 0 0 0 7 8 5 2 3 8}$ & $\mathbf{3 0 6 0 0 0 1 2 6 2}$ \\
\hline set/15 & $1.862,84$ & 263,80 & 550,31 & $1.437,05$ \\
\hline out/15 & $2.317,41$ & 319,24 & 548,66 & $1.239,06$ \\
\hline nov/15 & $1.989,81$ & 323,25 & 652,67 & $1.040,19$ \\
\hline dez/15 & $3.090,84$ & 167,26 & 792,39 & 726,36 \\
\hline jan/16 & $2.019,38$ & 294,05 & 711,48 & 658,24 \\
\hline fev/16 & $4.574,84$ & 220,64 & 801,50 & 565,37 \\
\hline mar/16 & $2.006,23$ & 493,35 & 765,46 & 658,85 \\
\hline abr/16 & $3.175,10$ & 566,51 & 742,98 & 602,43 \\
\hline mai/16 & $2.402,54$ & 643,13 & 783,99 & 750,80 \\
\hline jun/16 & $2.090,61$ & 442,63 & - & 735,85 \\
\hline jul/16 & $2.433,14$ & 464,25 & 725,46 & 678,55 \\
\hline ago/16 & $2.223,49$ & 515,00 & 838,56 & 717,80 \\
\hline SOMAS & $30.186,23$ & $4.713,11$ & $7.913,46$ & $9.810,55$ \\
\cline { 2 - 5 } & \multicolumn{3}{|c|}{ OBS: Não há fatura no mês de jun-2016 na instalação 4000785238. }
\end{tabular}

\section{CONSIDERAÇÕES FINAIS}

O gerenciamento energético é de fundamental importância para qualquer instituição, uma vez que sua irregularidade apenas trará ônus à instituição, sendo, dessa forma, necessária uma continua gestão a fim de que todas as instalações permaneçam na regularidade.

Além disso, ficou claro, com o estudo, a necessidade de se conhecer as informações relacionadas com os fluxos de energia, pois se existe apenas um acompanhamento destes fluxos sem se conhecê-los, é impossível atuar com ações que busquem a melhor adequação de uma instalação, porém, conhecendo-os, é possível a realização de um prognóstico e colocar em prática estas medidas. 
Evidenciou-se que um acompanhamento dos índices de controle de consumo, possibilita, facilmente, encontrar possíveis divergências (irregularidades) e, conhecendo-as, é possível atuar de forma a convergi-las.

Comprovou-se que as simples medidas tomadas no gerenciamento energético de um sistema de saneamento básico obteve uma rentabilidade máxima, uma vez que não houve sequer investimentos, apenas economias reais.

Além disso, observou-se também, que todas as ações tomadas no gerenciamento energético do objeto de estudo não requereram investimentos, o que evidencia seu grande potencial para qualquer instituição, uma vez que após consumá-las, já se usufruirá das economias.

Portanto, ratifica-se o fato de que o gerenciamento energético trará grandes benefícios a qualquer instituição que aplicá-lo, seja para entrar na regularidade e não pagar multas, seja para permanecer da regularidade e não passar a pagá-las.

\section{REFERÊNCIAS}

ANEEL. Estabelece, de forma atualizada e consolidada, as Condições Gerais de Fornecimento de Energia Elétrica. Resolução n. 456, de 29 de novembro de 2000. Diário Oficial da União, Brasília, DF, 30 nov. 2000. Disponível em: <http://www2.aneel.gov.br/cedoc/res2000456.pdf>. Acesso em: 19 dez. 2016.

ANEEL. Estabelece as Condições Gerais de Fornecimento de Energia Elétrica de forma atualizada e consolidada. Resolução n. 414, de 9 de setembro de 2010. Diário Oficial da União, Brasília, DF, 15 set. 2010. Disponível em: <http://www2.aneel.gov.br/cedoc/ren2010414comp.pdf>. Acesso em: 15 mar. 2016.

ANEEL. Procedimento de Distribuição de Energia Elétrica no Sistema Elétrico Nacional: Módulo 8 - Qualidade de Energia Elétrica, 2016. Disponível em: <http://www2.aneel.gov.br/arquivos/PDF/M\%C3\%B3dulo8_Revis\%C3\%A3o_7.pdf>. Acesso em: 17 mar. 2016.

BRASIL. Lei n. 9.427, de 26 de dezembro de 1996. Institui a Agência Nacional de Energia Elétrica - ANEEL, disciplina o regime das concessões de serviços públicos de energia elétrica e dá outras providências. Diário Oficial da União, Brasília, DF, 27 dez. 1996. Disponível em: <http://www2.aneel.gov.br/cedoc/lei19969427.pdf>. Acesso em: 19 dez. 2016.

BRASIL. Decreto n. 7.891, de 23 de janeiro de 2013. Regulamenta a Lei no 12.783, de 11 de janeiro de 2013, dispõe sobre as concessões de geração, transmissão e distribuição de energia elétrica, sobre a redução dos encargos setoriais e sobre a modicidade tarifária, e a Medida Provisória $n^{\circ}$ 605, de 23 de janeiro de 2013, que altera a Lei no 10.438, de 26 de abril de 2002, e dá outras providências. Diário 
Oficial da União, Brasília, DF, 24 jan. 2013. Disponível em: <http://www.planalto.gov.br/ccivil_03/_ato2011-2014/2013/Decreto/D7891.htm>.

CPFL jaguari. Disponível em:

<https://www.cpflempresas.com.br/institucional/tarifas.aspx?emp=1>. Acesso em: 23 set. 2016.

ELETROBRÁS. Procel. Disponível em:

<http://www.eletrobras.com/elb/data/Pages/LUMIS0389BBA8PTBRIE.htm>. Acesso em: 19 dez. 2016.

FELTRIN, A. P. Instalações Elétricas Industriais: Correção do Fator de Potência em Sistemas Industriais. São Paulo: UNESP/ELE1093, 2013. p. 53. Apostila.

Disponível em:

<http://www.feis.unesp.br/Home/departamentos/engenhariaeletrica/capitulo-4-20152s-n.pdf>. Acesso em: 16 mar. 2016. Acesso em: 16 mar. 2016.

MARQUES, M. C. S.; HADDAD, J.; GUARDIA, E. C. (Org.). Eficiência Energética: Teoria \& Prática. 1 ed. p. 244, 2007. Disponível em: <http://arquivos.portaldaindustria.com.br/app/conteudo_18/2014/04/22/6281/Eficienci a_energetica_Teoria_e_pratica.pdf>. Acesso em: 11 mar. 2016.

SCHIMIDT, S. Desenvolvimento, Implantação e Avaliação de um Programa de Gerenciamento Energético Municipal: O Caso de Santa Helena (PR). 2004. 99f. Dissertação (Mestrado em Engenharia de Produção) - Programa de PósGraduação em Engenharia de Produção, Universidade Federal de Santa Catarina, Florianópolis, 2004. Disponível em:

<http://repositorio.ufsc.br/xmlui/handle/123456789/87881>. Acesso em: $19 \mathrm{dez}$. 2016.

SOUZA, H. M. de; LEONELLI, P. A.; PIRES, C. A. P.; SOUZA Jr, V. B.; PEREIRA, R. W. L. Reflexões sobre os Principias Programas em Eficiência Energética Existentes no Brasil. Revista Brasileira de Energia, v. 15, n. 1, p. 7-26, jan./jun. 2009. Disponível em: <http://new.sbpe.org.br/wpcontent/themes/sbpe/img/artigos_pdf/v15n01/v15n01a1.pdf>. Acesso em: 19 dez. 2016. 
APÊNDICE A LEVANTAMENTO DOS FLUXOS DE ENÉRGIA 
Histórico anual dos índices da Captação Jaguari.

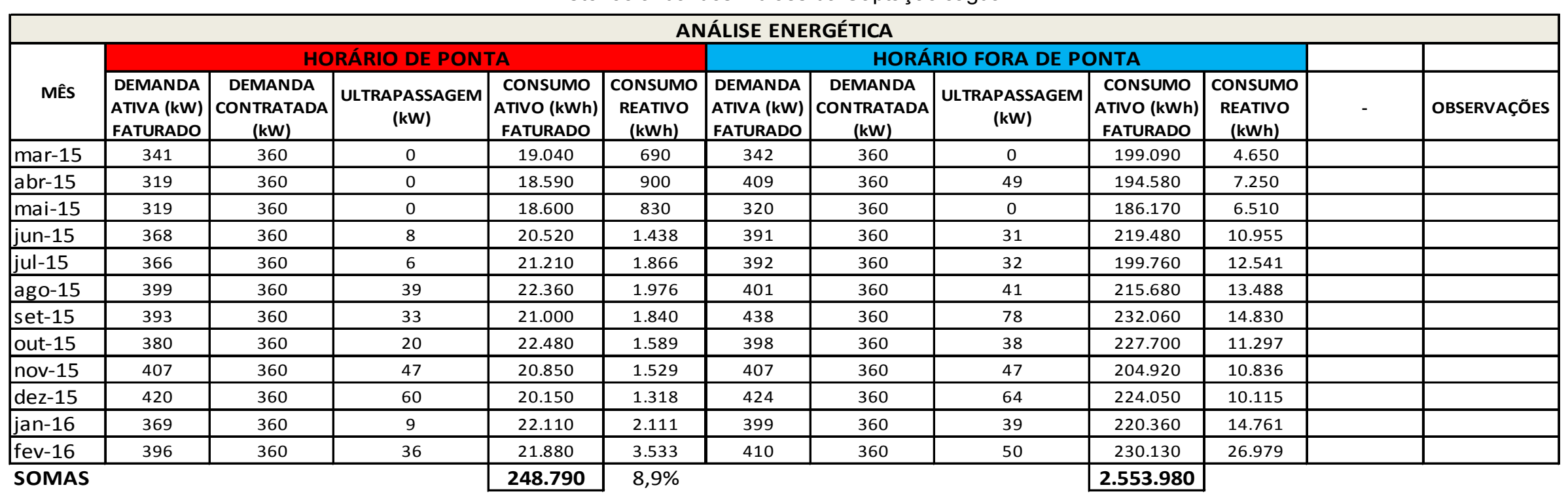

\begin{tabular}{|c|c|c|c|c|c|c|c|c|c|c|c|c|}
\hline \multicolumn{13}{|c|}{ ANÁLISE FINANCEIRA - R\$ } \\
\hline \multirow[b]{2}{*}{ MÊS } & \multicolumn{5}{|c|}{ HORÁRIO DE PONTA } & \multicolumn{5}{|c|}{ HORÁRIO FORA DE PONTA } & \multirow[b]{2}{*}{$\begin{array}{c}\text { IMPOSTOS E } \\
\text { OUTROS }\end{array}$} & \multirow[b]{2}{*}{$\begin{array}{l}\text { VALOR DA } \\
\text { CONTA }\end{array}$} \\
\hline & $\begin{array}{c}\text { DEMANDA } \\
\text { ATIVA }\end{array}$ & $\begin{array}{c}\text { DEMANDA } \\
\text { CONTRATADA } \\
\end{array}$ & ULTRAPASSAGEM & $\begin{array}{c}\text { CONSUMO } \\
\text { ATIVO }\end{array}$ & $\begin{array}{l}\text { ENERGIA } \\
\text { REATIVA } \\
\end{array}$ & $\begin{array}{c}\text { DEMANDA } \\
\text { ATIVA }\end{array}$ & $\begin{array}{c}\text { DEMANDA } \\
\text { CONTRATADA } \\
\end{array}$ & ULTRAPASSAGEM & $\begin{array}{c}\begin{array}{c}\text { CONSUMO } \\
\text { ATIVO }\end{array} \\
\end{array}$ & $\begin{array}{l}\text { ENERGIA } \\
\text { REATIVA } \\
\end{array}$ & & \\
\hline mar-15 & $5.504,94$ & 0,00 & 0,00 & $6.105,29$ & 146,43 & $1.915,56$ & 0,00 & 0,00 & $45.062,53$ & 986,82 & $33.609,12$ & $93.330,69$ \\
\hline abr-15 & $5.504,94$ & 0,00 & 0,00 & $5.814,15$ & 179,52 & $2.176,29$ & 0,00 & 613,48 & $42.452,97$ & $1.446,15$ & $34.003,10$ & $92.190,60$ \\
\hline mai-15 & $5.504,94$ & 0,00 & 0,00 & $5.739,66$ & 161,48 & $1.915,56$ & 0,00 & 0,00 & $39.841,22$ & $1.266,58$ & $36.204,85$ & $90.634,29$ \\
\hline jun-15 & $5.627,27$ & 0,00 & 0,00 & $6.332,14$ & 449,61 & $2.080,51$ & 0,00 & 388,12 & $46.969,71$ & $2.161,73$ & $44.805,52$ & $108.814,61$ \\
\hline jul-15 & $5.596,69$ & 0,00 & 0,00 & $6.545,07$ & 533,27 & $2.085,83$ & 0,00 & 400,54 & $42.747,54$ & $2.506,60$ & $38.220,50$ & $98.636,04$ \\
\hline ago-15 & $6.101,31$ & 0,00 & $1.403,22$ & $6.899,94$ & 602,80 & $2.133,72$ & 0,00 & 513,32 & $46.156,48$ & $2.854,71$ & $41.713,16$ & $108.378,66$ \\
\hline set-15 & $6.009,56$ & 0,00 & 1187,34 & $6.480,26$ & 539,95 & $2.330,60$ & 0,00 & 976,56 & $49.661,88$ & $2.885,32$ & $42.359,39$ & $112.430,86$ \\
\hline out-15 & $5.810,77$ & 0,00 & 719,60 & $6.936,97$ & 424,40 & $2.117,76$ & 0,00 & 475,76 & $48.728,82$ & $2.301,06$ & $40.414,69$ & $107.929,83$ \\
\hline nov-15 & $6.223,64$ & 0,00 & $1.691,06$ & $6.433,98$ & 473,38 & $2.165,65$ & 0,00 & 588,44 & $43.853,80$ & $2.326,61$ & $37.683,55$ & $101.440,11$ \\
\hline dez-15 & $6.422,43$ & 0,00 & $2.158,80$ & $6.217,97$ & 426,26 & $2.256,10$ & 0,00 & 801,28 & $47.947,71$ & $2.119,61$ & $38.598,18$ & $106.948,34$ \\
\hline jan-16 & $5.642,56$ & 0,00 & 0,00 & $6.822,79$ & 598,75 & $2.123,08$ & 0,00 & 488,28 & $47.158,03$ & $2.999,27$ & $37.311,63$ & $103.144,39$ \\
\hline fev-16 & $6.055,43$ & 0,00 & $1.295,28$ & $6.751,82$ & $1.069,51$ & $2.181,61$ & 0,00 & 626,00 & $49.248,86$ & $5.606,90$ & $37.732,47$ & $110.567,88$ \\
\hline SOMAS & $70.004,48$ & & $8.455,30$ & $77.080,04$ & $5.605,36$ & $25.482,27$ & & $5.871,78$ & $549.829,55$ & $29.461,36$ & $462.656,16$ & $1.234 .446,30$ \\
\hline
\end{tabular}

ISSN 1679-8902 
Histórico anual dos índices da ETA Central.

\begin{tabular}{|c|c|c|c|c|c|c|c|c|c|c|c|c|}
\hline \multicolumn{13}{|c|}{ ANÁLISE ENERGÉTICA } \\
\hline \multirow[b]{2}{*}{ MÊS } & \multicolumn{5}{|c|}{ HORÁRIO DE PONTA } & \multicolumn{5}{|c|}{ HORÁRIO FORA DE PONTA } & & \multirow[b]{2}{*}{ OBSERVAÇÕES } \\
\hline & $\begin{array}{l}\text { DEMANDA } \\
\text { ATIVA (kW) } \\
\text { FATURADO }\end{array}$ & \begin{tabular}{|c|} 
DEMANDA \\
CONTRATADA \\
$(\mathrm{kW})$
\end{tabular} & $\begin{array}{c}\text { ULTRAPASSAGEM } \\
\text { (kW) }\end{array}$ & $\begin{array}{l}\text { CONSUMO } \\
\text { ATIVO (kWh) } \\
\text { FATURADO } \\
\end{array}$ & $\begin{array}{c}\text { CONSUMO } \\
\text { REATIVO } \\
(\mathrm{kWh}) \\
\end{array}$ & $\begin{array}{l}\text { DEMANDA } \\
\text { ATIVA (kW) } \\
\text { FATURADO }\end{array}$ & $\begin{array}{c}\text { DEMANDA } \\
\text { CONTRATADA } \\
\text { (kW) }\end{array}$ & $\begin{array}{l}\text { ULTRAPASSAGEM } \\
(\mathbf{k W})\end{array}$ & \begin{tabular}{|c|} 
CONSUMO \\
ATIVO (kWh) \\
FATURADO \\
\end{tabular} & $\begin{array}{l}\text { CONSUMO } \\
\text { REATIVO } \\
\text { (kWh) }\end{array}$ & - & \\
\hline mar-15 & 223 & 220 & 3 & 12.556 & 536 & 223 & 220 & 3 & 119.690 & 4.540 & & \\
\hline abr-15 & 225 & 220 & 5 & 12.293 & 499 & 226 & 220 & 6 & 116.344 & 4.349 & & \\
\hline mai-15 & 225 & 220 & 5 & 12.448 & 491 & 226 & 220 & 6 & 113.311 & 4.176 & & \\
\hline jun-15 & 228 & 220 & 8 & 12.892 & 550 & 228 & 220 & 8 & 126.274 & 4.680 & & \\
\hline jul-15 & 229 & 220 & 9 & 13.259 & 564 & 229 & 220 & 9 & 112.373 & 4.236 & & \\
\hline ago-15 & 228 & 220 & 8 & 13.813 & 607 & 227 & 220 & 7 & 119.315 & 4.468 & & \\
\hline set-15 & 229 & 220 & 9 & 12.441 & 556 & 226 & 220 & 6 & 126.566 & 4.782 & & \\
\hline out-15 & 226 & 220 & 6 & 13.652 & 582 & 226 & 220 & 6 & 126.074 & 4.478 & & \\
\hline nov-15 & 229 & 220 & 9 & 12.552 & 543 & 231 & 220 & 11 & 115.338 & 4.108 & & \\
\hline dez-15 & 229 & 220 & 9 & 11.727 & 543 & 229 & 220 & 9 & 125.515 & 4.548 & & \\
\hline jan-16 & 230 & 220 & 10 & 13.516 & 649 & 227 & 220 & 7 & 125.635 & 4.681 & & \\
\hline fev-16 & 228 & 220 & 8 & 12.722 & 589 & 230 & 220 & 10 & 125.178 & 4.454 & & \\
\hline SOMAS & & & & 153.871 & $9,6 \%$ & & & & 1.451 .613 & & & \\
\hline
\end{tabular}

\begin{tabular}{|c|c|c|c|c|c|c|c|c|c|c|c|c|}
\hline \multicolumn{13}{|c|}{ ANÁLISE FINANCEIRA - R\$ } \\
\hline \multirow[b]{2}{*}{ MÊS } & \multicolumn{5}{|c|}{ HORÁRIO DE PONTA } & \multicolumn{5}{|c|}{ HORÁRIO FORA DE PONTA } & \multirow[b]{2}{*}{\begin{tabular}{|c|} 
IMPOSTOS E \\
OUTROS
\end{tabular}} & \multirow[b]{2}{*}{$\begin{array}{l}\text { VALOR DA } \\
\text { CONTA }\end{array}$} \\
\hline & $\begin{array}{c}\text { DEMANDA } \\
\text { ATIVA }\end{array}$ & \begin{tabular}{|c|} 
DEMANDA \\
CONTRATADA
\end{tabular} & ULTRAPASSAGEM & $\begin{array}{c}\text { CONSUMO } \\
\text { ATIVO }\end{array}$ & $\begin{array}{l}\text { ENERGIA } \\
\text { REATIVA }\end{array}$ & $\begin{array}{c}\text { DEMANDA } \\
\text { ATIVA }\end{array}$ & \begin{tabular}{|c|} 
DEMANDA \\
CONTRATADA
\end{tabular} & ULTRAPASSAGEM & $\begin{array}{c}\text { CONSUMO } \\
\text { ATIVO }\end{array}$ & $\begin{array}{l}\text { ENERGIA } \\
\text { REATIVA }\end{array}$ & & \\
\hline mar-15 & $3.410,00$ & \begin{tabular}{|l|}
0,00 \\
\end{tabular} & 0,00 & $4.026,15$ & 162,14 & $1.186,58$ & 0,00 & 0,00 & $27.090,93$ & 987,66 & $20.565,89$ & $57.429,35$ \\
\hline abr-15 & $3.440,59$ & 0,00 & 0,00 & $3.844,71$ & 139,96 & $1.202,55$ & 0,00 & 0,00 & $25.383,63$ & 903,85 & $20.332,89$ & $55.248,18$ \\
\hline mai-15 & $3.440,59$ & 0,00 & 0,00 & $3.841,25$ & 144,05 & $1.202,55$ & 0,00 & 0,00 & $24.249,07$ & 861,01 & $22.350,53$ & $56.089,05$ \\
\hline jun-15 & $3.486,46$ & 0,00 & 0,00 & $3.978,26$ & 161,59 & $1.213,19$ & 0,00 & 0,00 & $27.023,20$ & 953,00 & $25.879,58$ & $62.695,28$ \\
\hline jul-15 & $3.501,75$ & 0,00 & 0,00 & $4.091,50$ & 158,24 & $1.218,51$ & 0,00 & 0,00 & $24.046,33$ & 873,05 & $21.595,16$ & $55.484,54$ \\
\hline ago-15 & $3.486,46$ & 0,00 & 0,00 & $4.262,48$ & 166,62 & $1.207,87$ & 0,00 & 0,00 & $25.533,95$ & 917,81 & $22.774,77$ & $58.349,96$ \\
\hline set-15 & $3.501,75$ & 0,00 & 0,00 & $3.839,10$ & 162,76 & $1.202,55$ & 0,00 & 0,00 & $27.085,69$ & 978,91 & $22.714,40$ & $59.485,16$ \\
\hline out-15 & $3.455,88$ & 0,00 & 0,00 & $4.212,78$ & 161,76 & $1.202,55$ & 0,00 & 0,00 & $26.980,41$ & 913,69 & $22.338,31$ & $59.265,38$ \\
\hline nov-15 & $3.532,34$ & 0,00 & 0,00 & $3.873,35$ & 154,17 & $1.218,51$ & 0,00 & 0,00 & $24.682,85$ & 841,71 & $20.758,23$ & $55.061,16$ \\
\hline dez-15 & $3.501,75$ & 0,00 & 0,00 & $3.618,77$ & 154,17 & $1.218,51$ & 0,00 & 0,00 & $26.860,77$ & 927,32 & $21.035,14$ & $57.316,43$ \\
\hline jan-16 & $3.517,05$ & 0,00 & 0,00 & $4.170,82$ & 174,79 & $1.207,87$ & 0,00 & 0,00 & $26.886,45$ & 953,19 & $21.168,90$ & $58.079,07$ \\
\hline fev-16 & $3.486,46$ & 0,00 & 0,00 & $3.925,80$ & 175,25 & $1.223,83$ & 0,00 & 0,00 & $26.788,65$ & 921,16 & $19.584,91$ & $56.106,06$ \\
\hline SOMAS & $41.761,08$ & & 0,00 & $47.684,97$ & $1.915,50$ & $14.505,07$ & & 0,00 & $312.611,93$ & $11.032,36$ & $261.098,71$ & $690.609,62$ \\
\hline
\end{tabular}

ISSN 1679-8902 
No38 Vol 12017

Histórico anual dos índices da Estação Elevatória de Esgoto Central.

\begin{tabular}{|c|c|c|c|c|c|c|c|c|c|c|c|c|}
\hline \multicolumn{13}{|c|}{ ANÁLISE ENERGÉTICA } \\
\hline \multirow[b]{2}{*}{ MÊS } & \multicolumn{5}{|c|}{ HORÁRIO DE PONTA } & \multicolumn{5}{|c|}{ HORÁRIO FORA DE PONTA } & & \multirow[b]{2}{*}{ OBSERVAÇÕES } \\
\hline & $\begin{array}{l}\text { DEMANDA } \\
\text { ATIVA (kW) } \\
\text { FATURADO }\end{array}$ & \begin{tabular}{|c|} 
DEMANDA \\
CONTRATADA \\
$(\mathrm{kW})$
\end{tabular} & $\begin{array}{c}\text { ULTRAPASSAGEM } \\
\text { (kW) }\end{array}$ & \begin{tabular}{|c|} 
CONSUMO \\
ATIVO (kWh) \\
FATURADO
\end{tabular} & $\begin{array}{l}\text { CONSUMO } \\
\text { REATIVO } \\
\text { (kWh) }\end{array}$ & \begin{tabular}{|l|} 
DEMANDA \\
ATIVA (kW) \\
FATURADO
\end{tabular} & \begin{tabular}{|c|} 
DEMANDA \\
CONTRATADA \\
$(\mathrm{kW})$
\end{tabular} & $\begin{array}{c}\text { ULTRAPASSAGEM } \\
(\mathrm{kW})\end{array}$ & $\begin{array}{c}\text { CONSUMO } \\
\text { ATIVO (kWh) } \\
\text { FATURADO }\end{array}$ & $\begin{array}{l}\text { CONSUMO } \\
\text { REATIVO } \\
\text { (kWh) }\end{array}$ & - & \\
\hline mar-15 & 39 & 50 & 0 & 1.840 & 425 & 46 & 50 & 0 & 15.730 & 2.710 & & \\
\hline$a b r-15$ & 38 & 50 & 0 & 1.745 & 390 & 45 & 50 & 0 & 14.780 & 2.870 & & \\
\hline mai-15 & 38 & 50 & 0 & 1.660 & 390 & 38 & 50 & 0 & 13.275 & 2.510 & & \\
\hline jun-15 & 37 & 50 & 0 & 1.770 & 385 & 48 & 50 & 0 & 14.515 & 2.740 & & \\
\hline jul-15 & 39 & 50 & 0 & 1.800 & 390 & 39 & 50 & 0 & 13.710 & 2.560 & & \\
\hline ago-15 & 42 & 50 & 0 & 1.905 & 465 & 41 & 50 & 0 & 13.800 & 2.955 & & \\
\hline set-15 & 41 & 50 & 0 & 1.855 & 415 & 46 & 50 & 0 & 17.345 & 3.055 & & \\
\hline out-15 & 43 & 50 & 0 & 1.865 & 435 & 50 & 50 & 0 & 16.775 & 2.945 & & \\
\hline nov-15 & 52 & 50 & 2 & 2.075 & 380 & 52 & 50 & 2 & 17.105 & 2.560 & & \\
\hline dez-15 & 53 & 50 & 3 & 2.080 & 367 & 52 & 50 & 2 & 19.110 & 2.895 & & \\
\hline jan-16 & 56 & 50 & 6 & 2.340 & 430 & 55 & 50 & 5 & 19.855 & 3.024 & & \\
\hline fev-16 & 47 & 50 & 0 & 2.130 & 355 & 55 & 50 & 5 & 18.560 & 2.558 & & \\
\hline SOMAS & & & & 23.065 & $10,6 \%$ & & & & 194.560 & & & \\
\hline
\end{tabular}

\begin{tabular}{|c|c|c|c|c|c|c|c|c|c|c|c|c|}
\hline \multicolumn{13}{|c|}{ ANÁLISE FINANCEIRA - R\$ } \\
\hline \multirow[b]{2}{*}{ MÊS } & \multicolumn{5}{|c|}{ HORÁRIO DE PONTA } & \multicolumn{5}{|c|}{ HORÁRIO FORA DE PONTA } & \multirow[b]{2}{*}{$\begin{array}{c}\text { IMPOSTOS E } \\
\text { OUTROS }\end{array}$} & \multirow[b]{2}{*}{$\begin{array}{l}\text { VALOR DA } \\
\text { CONTA }\end{array}$} \\
\hline & $\begin{array}{c}\text { DEMANDA } \\
\text { ATIVA }\end{array}$ & \begin{tabular}{|c|} 
DEMANDA \\
CONTRATADA \\
\end{tabular} & ULTRAPASSAGEM & $\begin{array}{c}\text { CONSUMO } \\
\text { ATIVO }\end{array}$ & $\begin{array}{l}\text { ENERGIA } \\
\text { REATIVA } \\
\end{array}$ & $\begin{array}{c}\text { DEMANDA } \\
\text { ATIVA }\end{array}$ & $\begin{array}{c}\text { DEMANDA } \\
\text { CONTRATADA } \\
\end{array}$ & ULTRAPASSAGEM & $\begin{array}{c}\text { CONSUMO } \\
\text { ATIVO } \\
\end{array}$ & $\begin{array}{l}\text { ENERGIA } \\
\text { REATIVA } \\
\end{array}$ & & \\
\hline mar-15 & 764,58 & 0,00 & 0,00 & 590,00 & 90,19 & 266,05 & 0,00 & 0,00 & $3.560,36$ & 575,11 & $3.012,63$ & $8.858,92$ \\
\hline abr-15 & 764,58 & 0,00 & 0,00 & 545,76 & 77,79 & 266,05 & 0,00 & 0,00 & $3.224,66$ & 532,58 & $2.893,14$ & $8.304,56$ \\
\hline mai-15 & 764,58 & 0,00 & 0,00 & 512,25 & 75,88 & 266,05 & 0,00 & 0,00 & $2.840,90$ & 488,35 & $3.001,55$ & $7.949,56$ \\
\hline jun-15 & 764,58 & 0,00 & 0,00 & 546,19 & 74,90 & 266,05 & 0,00 & 0,00 & $3.106,28$ & 533,09 & $3.420,28$ & $8.711,37$ \\
\hline jul-15 & 764,58 & 0,00 & 0,00 & 555,45 & 75,88 & 266,05 & 0,00 & 0,00 & $2.934,01$ & 496,07 & $2.983,11$ & $8.075,15$ \\
\hline ago-15 & 764,58 & 0,00 & 0,00 & 587,85 & 90,47 & 266,05 & 0,00 & 0,00 & $2.953,27$ & 574,93 & $3.048,57$ & $8.285,72$ \\
\hline set-15 & 764,58 & 0,00 & 0,00 & 572,42 & 80,75 & 266,05 & 0,00 & 0,00 & $3.711,90$ & 594,38 & $3.460,11$ & $9.450,19$ \\
\hline out-15 & 764,58 & 0,00 & 0,00 & 575,51 & 84,64 & 266,05 & 0,00 & 0,00 & $3.589,92$ & 603,31 & $3.313,57$ & $9.197,58$ \\
\hline nov-15 & 795,16 & 0,00 & 0,00 & 640,31 & 73,93 & 276,69 & 0,00 & 0,00 & $3.660,55$ & 528,40 & $3.406,20$ & $9.381,24$ \\
\hline dez-15 & 810,45 & 0,00 & 0,00 & 641,86 & 113,86 & 276,69 & 0,00 & 0,00 & $4.089,62$ & 593,58 & $3.550,68$ & $10.076,74$ \\
\hline jan-16 & 856,32 & 0,00 & 215,88 & 722,09 & 83,66 & 292,66 & 0,00 & 62,60 & $4.249,05$ & 612,61 & $3.762,20$ & $10.857,07$ \\
\hline fev-16 & 764,58 & 0,00 & 0,00 & 657,29 & 69,07 & 292,66 & 0,00 & 62,60 & $3.971,92$ & 515,88 & $3.235,85$ & $9.569,85$ \\
\hline SOMAS & $9.343,15$ & & 215,88 & $7.146,98$ & 991,02 & $3.267,10$ & & 125,20 & $41.892,44$ & $6.648,29$ & $39.087,89$ & $108.717,95$ \\
\hline
\end{tabular}

ISSN 1679-8902 
Histórico anual dos índices dos Booster's da ETA.

\begin{tabular}{|c|c|c|c|c|c|c|c|c|c|c|c|c|}
\hline \multicolumn{13}{|c|}{ ANÁLISE ENERGÉTICA } \\
\hline \multirow[b]{2}{*}{ MÊS } & \multicolumn{5}{|c|}{ HORÁRIO DE PONTA } & \multicolumn{5}{|c|}{\begin{tabular}{|l|} 
HORÁRIO FORA DE PONTA \\
\end{tabular}} & \multirow[b]{2}{*}{-} & \multirow[b]{2}{*}{ OBSERVAÇÕES } \\
\hline & $\begin{array}{l}\text { DEMANDA } \\
\text { ATIVA (kW) } \\
\text { FATURADO } \\
\end{array}$ & \begin{tabular}{|c|} 
DEMANDA \\
CONTRATADA \\
$(\mathrm{kW})$ \\
\end{tabular} & $\begin{array}{l}\text { ULTRAPASSAGEM } \\
\text { (kW) }\end{array}$ & \begin{tabular}{|c|} 
CONSUMO \\
ATIVO (kWh) \\
FATURADO \\
\end{tabular} & \begin{tabular}{|c|} 
CONSUMO \\
REATIVO \\
(kWh) \\
\end{tabular} & \begin{tabular}{|l|} 
DEMANDA \\
ATIVA (kW) \\
FATURADO \\
\end{tabular} & \begin{tabular}{|c|} 
DEMANDA \\
CONTRATADA \\
$(\mathrm{kW})$ \\
\end{tabular} & $\begin{array}{c}\text { ULTRAPASSAGEM } \\
(\mathrm{kW})\end{array}$ & \begin{tabular}{|c|} 
CONSUMO \\
ATIVO (kWh) \\
FATURADO \\
\end{tabular} & \begin{tabular}{|c|} 
CONSUMO \\
REATIVO \\
(kWh)
\end{tabular} & & \\
\hline mar-15 & 53 & 65 & 0 & 2.902 & 315 & 77 & 90 & 0 & 29.018 & 2.753 & & \\
\hline$a b r-15$ & 77 & 65 & 12 & 3.036 & 358 & 79 & 90 & 0 & 30.703 & 2.986 & & \\
\hline mai-15 & 78 & 65 & 13 & 2.856 & 333 & 79 & 90 & 0 & 29.246 & 2.861 & & \\
\hline jun-15 & 51 & 65 & 0 & 2.927 & 344 & 76 & 90 & 0 & 31.209 & 3.216 & & \\
\hline ago-15 & 52 & 65 & 0 & 3.109 & 337 & 75 & 90 & 0 & 29.559 & 2.726 & & \\
\hline set-15 & 55 & 65 & 0 & 2.910 & 309 & 75 & 90 & 0 & 31.264 & 2.817 & & \\
\hline out-15 & 54 & 65 & 0 & 3.086 & 351 & 76 & 90 & 0 & 31.319 & 2.876 & & \\
\hline nov-15 & 54 & 65 & 0 & 2.802 & 332 & 78 & 90 & 0 & 28.574 & 2.742 & & \\
\hline dez-15 & 54 & 65 & 0 & 2.790 & 330 & 75 & 90 & 0 & 31.504 & 2.860 & & \\
\hline jan-16 & 54 & 65 & 0 & 3.023 & 344 & 59 & 90 & 0 & 30.997 & 2.593 & & \\
\hline fev-16 & 77 & 65 & 12 & 3.271 & 344 & 77 & 90 & 0 & 33.215 & 2.962 & & \\
\hline SOMAS & & & & 35.615 & $8,9 \%$ & & & & 364.547 & & & \\
\hline
\end{tabular}

\begin{tabular}{|c|c|c|c|c|c|c|c|c|c|c|c|c|}
\hline \multicolumn{13}{|c|}{ ANÁLISE FINANCEIRA - R\$ } \\
\hline \multirow[b]{2}{*}{ MÊS } & \multicolumn{5}{|c|}{ HORÁRIO DE PONTA } & \multicolumn{5}{|c|}{ HORÁRIO FORA DE PONTA } & \multirow[b]{2}{*}{$\begin{array}{l}\text { IMPOSTOS E } \\
\text { OUTROS }\end{array}$} & \multirow[b]{2}{*}{$\begin{array}{l}\text { VALOR DA } \\
\text { CONTA }\end{array}$} \\
\hline & $\begin{array}{c}\text { DEMANDA } \\
\text { ATIVA }\end{array}$ & \begin{tabular}{|c|} 
DEMANDA \\
CONTRATADA
\end{tabular} & ULTRAPASSAGEM & $\begin{array}{l}\text { CONSUMO } \\
\text { ATIVO }\end{array}$ & $\begin{array}{l}\text { ENERGIA } \\
\text { REATIVA }\end{array}$ & $\begin{array}{l}\text { DEMANDA } \\
\text { ATIVA }\end{array}$ & \begin{tabular}{|c|} 
DEMANDA \\
CONTRATADA
\end{tabular} & ULTRAPASSAGEM & $\begin{array}{c}\text { CONSUMO } \\
\text { ATIVO }\end{array}$ & $\begin{array}{l}\text { ENERGIA } \\
\text { REATIVA }\end{array}$ & & \\
\hline mar-15 & 993,95 & 0,00 & 0,00 & 930,54 & 66,84 & 478,89 & 0,00 & 0,00 & $6.568,01$ & 584,25 & $5.178,79$ & $14.801,27$ \\
\hline$a b r-15$ & $1.177,45$ & 0,00 & 431,76 & 949,53 & 113,83 & 478,89 & 0,00 & 0,00 & $6.698,70$ & 595,82 & $5.710,83$ & $16.156,81$ \\
\hline mai-15 & $1.192,74$ & 0,00 & 467,74 & 881,32 & 107,25 & 478,89 & 0,00 & 0,00 & $6.258,78$ & 560,53 & $6.188,16$ & $16.135,41$ \\
\hline jun-15 & 993,95 & 0,00 & 0,00 & 903,23 & 66,93 & 478,89 & 0,00 & 0,00 & $6.678,86$ & 625,71 & $6.631,12$ & $16.378,69$ \\
\hline jul-15 & 993,95 & 0,00 & 0,00 & 895,82 & 61,66 & 478,89 & 0,00 & 0,00 & $5.979,08$ & 503,72 & $5.507,32$ & $14.420,44$ \\
\hline ago-15 & 993,95 & 0,00 & 0,00 & 959,39 & 65,57 & 478,89 & 0,00 & 0,00 & $6.325,76$ & 530,37 & $5.805,68$ & $15.159,61$ \\
\hline set-15 & 993,95 & 0,00 & 0,00 & 897,99 & 60,12 & 478,89 & 0,00 & 0,00 & $6.690,63$ & 548,08 & $5.809,01$ & $15.478,67$ \\
\hline out-15 & 993,95 & 0,00 & 0,00 & 952,29 & 68,29 & 478,89 & 0,00 & 0,00 & $6.702,40$ & 559,56 & $5.732,19$ & $15.487,57$ \\
\hline nov-15 & 993,95 & 0,00 & 0,00 & 864,66 & 64,59 & 478,89 & 0,00 & 0,00 & $6.114,97$ & 533,48 & $5.316,26$ & $14.366,80$ \\
\hline dez-15 & 993,95 & 0,00 & 0,00 & 860,95 & 64,21 & 478,89 & 0,00 & 0,00 & $6.742,00$ & 556,44 & $5.463,90$ & $15.160,34$ \\
\hline jan-16 & 993,95 & 0,00 & 0,00 & 932,86 & 66,93 & 478,89 & 0,00 & 0,00 & $6.633,49$ & 504,49 & $5.367,63$ & $14.978,24$ \\
\hline fev-16 & \begin{tabular}{|l|}
$1.177,45$ \\
\end{tabular} & 0,00 & 431,76 & $1.009,38$ & 115,45 & 478,89 & 0,00 & 0,00 & $7.108,16$ & 523,75 & $5.586,83$ & $16.431,67$ \\
\hline SOMAS & $12.493,19$ & & $1.331,26$ & $11.037,96$ & 921,67 & $5.746,68$ & & 0,00 & $78.500,84$ & $6.626,20$ & $68.297,72$ & $184.955,52$ \\
\hline
\end{tabular}

ISSN 1679-8902 
Histórico anual dos índices da Estação Elevatória de Esgoto 09.

\begin{tabular}{|c|c|c|c|c|c|c|c|}
\hline \multicolumn{8}{|c|}{ ANÁLISE ENERGÉTICA } \\
\hline MÊS & $\begin{array}{l}\text { DEMANDA } \\
\text { ATIVA (kW) } \\
\text { FATURADO }\end{array}$ & $\begin{array}{c}\text { DEMANDA } \\
\text { CONTRATADA } \\
\text { (kW) }\end{array}$ & $\begin{array}{l}\text { ULTRAPASSAGEM } \\
\text { (kW) }\end{array}$ & $\begin{array}{l}\text { CONSUMO } \\
\text { ATIVO (kWh) } \\
\text { FATURADO }\end{array}$ & $\begin{array}{l}\text { CONSUMO } \\
\text { REATIVO } \\
\text { (kWh) }\end{array}$ & - & OBSERVAÇÕES \\
\hline mar-15 & 69 & 30 & 39 & 21.933 & $\mathrm{O}$ & & \\
\hline$a b r-15$ & 72 & 30 & 42 & 25.530 & $\mathrm{O}$ & & \\
\hline mai-15 & 81 & 30 & 51 & 23.422 & 0 & & \\
\hline jun-15 & 87 & 30 & 57 & 27.056 & 0 & & \\
\hline jul-15 & 69 & 30 & 39 & 22.920 & $\mathrm{O}$ & & \\
\hline ago-15 & 63 & 30 & 33 & 24.474 & $\mathrm{O}$ & & \\
\hline set-15 & 117 & 30 & 87 & 35.009 & 0 & & \\
\hline out-15 & 129 & 30 & 99 & 33.181 & $\mathrm{O}$ & & \\
\hline nov-15 & 114 & 30 & 84 & 34.446 & 0 & & \\
\hline dez-15 & 140 & 30 & 110 & 34.214 & 0 & & \\
\hline jan-16 & 124 & 30 & 94 & 36.396 & 0 & & \\
\hline fev-16 & 108 & 30 & 78 & 34.276 & 0 & & \\
\hline \multicolumn{4}{|l|}{ SOMAS } & 352.857 & & & \\
\hline
\end{tabular}

\begin{tabular}{|c|c|c|c|c|c|c|c|}
\hline \multicolumn{8}{|c|}{ ANÁLISE FINANCEIRA - R\$ } \\
\hline MÊS & $\begin{array}{c}\text { DEMANDA } \\
\text { ATIVA }\end{array}$ & \begin{tabular}{|c|} 
DEMANDA \\
CONTRATADA \\
\end{tabular} & ULTRAPASSAGEM & $\begin{array}{c}\text { CONSUMO } \\
\text { ATIVO }\end{array}$ & $\begin{array}{l}\text { ENERGIA } \\
\text { REATIVA } \\
\end{array}$ & $\begin{array}{c}\text { IMPOSTOS E } \\
\text { OUTROS }\end{array}$ & $\begin{array}{l}\text { VALOR DA } \\
\text { CONTA } \\
\end{array}$ \\
\hline mar-15 & $1.126,67$ & 0,00 & $1.498,38$ & $4.907,67$ & 0,00 & $3.634,58$ & $11.167,30$ \\
\hline abr-15 & $1.175,65$ & 0,00 & $1.613,64$ & $5.858,00$ & 0,00 & $4.536,50$ & $13.183,79$ \\
\hline mai-15 & $1.322,61$ & 0,00 & $1.959,42$ & $5.196,97$ & 0,00 & $4.944,03$ & $13.423,03$ \\
\hline jun-15 & $1.420,58$ & 0,00 & $2.189,94$ & $6.003,30$ & 0,00 & $5.980,40$ & $15.594,22$ \\
\hline jul-15 & $1.126,67$ & 0,00 & $1.498,38$ & $5.085,58$ & 0,00 & $4.450,35$ & $12.160,98$ \\
\hline ago-15 & $1.028,70$ & 0,00 & $1.267,86$ & $5.430,38$ & 0,00 & $4.582,02$ & $12.308,96$ \\
\hline set-15 & $1.910,43$ & 0,00 & $3.342,54$ & $7.767,93$ & 0,00 & $7.100,75$ & $20.121,65$ \\
\hline out-15 & $2.106,38$ & 0,00 & $3.803,58$ & $7.362,33$ & 0,00 & $6.818,16$ & $20.090,45$ \\
\hline nov-15 & $1.861,45$ & 0,00 & $3.227,28$ & $7.643,03$ & 0,00 & $6.762,48$ & $19.494,24$ \\
\hline dez-15 & $2.285,99$ & 0,00 & $4.226,20$ & $7.591,55$ & 0,00 & $6.847,95$ & $20.951,69$ \\
\hline jan-16 & $2.024,73$ & 0,00 & $3.611,48$ & $8.075,70$ & 0,00 & $6.798,67$ & $20.510,58$ \\
\hline fev-16 & $1.763,48$ & 0,00 & $2.996,76$ & $7.605,29$ & 0,00 & $6.118,30$ & $18.483,83$ \\
\hline SOMAS & $19.153,34$ & & $31.235,46$ & $78.527,73$ & 0,00 & $68.574,19$ & $197.490,72$ \\
\hline
\end{tabular}

ISSN 1679-8902 
Histórico anual dos índices da Estação de Tratamento de Esgoto Camanducaia.

\begin{tabular}{|c|c|c|c|c|c|c|c|c|c|c|c|c|}
\hline \multicolumn{13}{|c|}{ ANÁLISE ENERGÉTICA } \\
\hline \multirow[b]{2}{*}{ MÊS } & \multicolumn{5}{|c|}{ HORÁRIO DE PONTA } & \multicolumn{5}{|c|}{\begin{tabular}{|c|} 
HORÁRIO FORA DE PONTA \\
\end{tabular}} & & \multirow[b]{2}{*}{ OBSERVAÇÕES } \\
\hline & $\begin{array}{l}\text { DEMANDA } \\
\text { ATIVA (kW) } \\
\text { FATURADO } \\
\end{array}$ & \begin{tabular}{|c|} 
DEMANDA \\
CONTRATADA \\
$(\mathbf{k W})$ \\
\end{tabular} & \begin{tabular}{|c|}
$\begin{array}{c}\text { ULTRAPASSAGEM } \\
(\mathrm{kW})\end{array}$ \\
\end{tabular} & \begin{tabular}{|c|} 
CONSUMO \\
ATIVO (kWh) \\
FATURADO \\
\end{tabular} & $\begin{array}{c}\text { CONSUMO } \\
\text { REATIVO } \\
(\text { kWh })\end{array}$ & \begin{tabular}{|l|} 
DEMANDA \\
ATIVA (kW) \\
FATURADO \\
\end{tabular} & \begin{tabular}{|c|} 
DEMANDA \\
CONTRATADA \\
$(\mathbf{k W})$ \\
\end{tabular} & $\begin{array}{l}\text { ULTRAPASSAGEM } \\
\text { (kW) }\end{array}$ & \begin{tabular}{|l|} 
CONSUMO \\
ATIVO (kWh) \\
FATURADO \\
\end{tabular} & $\begin{array}{c}\text { CONSUMO } \\
\text { REATIVO } \\
\text { (kWh) } \\
\end{array}$ & - & \\
\hline mar-15 & 181 & 160 & 21 & 11.001 & 1.536 & 182 & 160 & 22 & 11.961 & 11.983 & & \\
\hline abr-15 & 190 & 160 & 30 & 10.024 & 1.504 & 190 & 160 & 30 & 110.466 & 12.026 & & \\
\hline mai-15 & 185 & 160 & 25 & 10.511 & 1.602 & 188 & 160 & 28 & 112.250 & 12.303 & & \\
\hline jun-15 & 195 & 160 & 35 & 11.086 & 1.696 & 202 & 160 & 42 & 123.144 & 13.723 & & \\
\hline ago-15 & 200 & 160 & 40 & 11.884 & 1.709 & 205 & 160 & 45 & 118.083 & 12.290 & & \\
\hline set-15 & 200 & 160 & 40 & 10.790 & 1.525 & 209 & 160 & 49 & 127.102 & 13.185 & & \\
\hline out-15 & 192 & 160 & 32 & 11.696 & 1.691 & 208 & 160 & 48 & 120.867 & 12.618 & & \\
\hline nov-15 & 198 & 160 & 38 & 10.412 & 1.558 & 203 & 160 & 43 & 113.381 & 12.223 & & \\
\hline dez-15 & 198 & 160 & 38 & 10.470 & 1.589 & 203 & 160 & 43 & 124.653 & 13.749 & & \\
\hline jan-16 & 185 & 160 & 25 & 10.684 & 1.661 & 188 & 160 & 28 & 115.531 & 12.862 & & \\
\hline fev-16 & 198 & 160 & 38 & 10.922 & 1.337 & 206 & 160 & 46 & 116.358 & 10.617 & & \\
\hline SOMAS & & & & 130.238 & $9,1 \%$ & & & & 1.301 .662 & & & \\
\hline
\end{tabular}

\begin{tabular}{|c|c|c|c|c|c|c|c|c|c|c|c|c|}
\hline \multicolumn{13}{|c|}{ ANÁLISE FINANCEIRA - R\$ } \\
\hline \multirow[b]{2}{*}{ MÊS } & \multicolumn{5}{|c|}{ HORÁRIO DE PONTA } & \multicolumn{5}{|c|}{ HORÁRIO FORA DE PONTA } & \multirow[b]{2}{*}{$\begin{array}{c}\text { IMPOSTOS E } \\
\text { OUTROS }\end{array}$} & \multirow[b]{2}{*}{$\begin{array}{l}\text { VALOR DA } \\
\text { CONTA }\end{array}$} \\
\hline & $\begin{array}{c}\text { DEMANDA } \\
\text { ATIVA }\end{array}$ & $\begin{array}{c}\text { DEMANDA } \\
\text { CONTRATADA }\end{array}$ & ULTRAPASSAGEM & $\begin{array}{c}\text { CONSUMO } \\
\text { ATIVO }\end{array}$ & $\begin{array}{l}\text { ENERGIA } \\
\text { REATIVA }\end{array}$ & $\begin{array}{l}\text { DEMANDA } \\
\text { ATIVA }\end{array}$ & $\begin{array}{c}\text { DEMANDA } \\
\text { CONTRATADA }\end{array}$ & ULTRAPASSAGEM & $\begin{array}{c}\text { CONSUMO } \\
\text { ATIVO }\end{array}$ & $\begin{array}{l}\text { ENERGIA } \\
\text { REATIVA }\end{array}$ & & \\
\hline mar-15 & $2.767,76$ & 0,00 & 755,58 & $3.527,54$ & 465,07 & 968,42 & 0,00 & 275,44 & $26.678,99$ & $2.676,09$ & $20.616,31$ & $58.731,20$ \\
\hline abr-15 & $2.905,39$ & 0,00 & $1.079,40$ & $3.135,08$ & 457,57 & $1.010,99$ & 0,00 & 375,60 & $24.101,19$ & $2.556,39$ & $19.854,36$ & $55.475,97$ \\
\hline mai-15 & $2.828,93$ & 0,00 & 899,50 & $3.243,53$ & 469,39 & $1.000,35$ & 0,00 & 350,56 & $24.022,00$ & $2.551,37$ & $22.631,64$ & $57.997,27$ \\
\hline jun-15 & $2.981,84$ & 0,00 & $1.259,30$ & $3.420,97$ & 518,00 & $1.074,84$ & 0,00 & 525,84 & $26.353,37$ & $2.833,72$ & $26.248,00$ & $65.215,88$ \\
\hline jul-15 & $2.874,80$ & 0,00 & $1.007,44$ & $3.319,74$ & 489,50 & $1.005,67$ & 0,00 & 363,08 & $23.083,81$ & $2.468,91$ & $21.220,40$ & $55.833,35$ \\
\hline set-15 & $3.058,30$ & 0,00 & $1.439,20$ & $3.329,62$ & 472,60 & $1.112,09$ & 0,00 & 613,48 & $27.200,40$ & $2.729,04$ & $23.639,70$ & $63.594,43$ \\
\hline out-15 & $2.935,97$ & 0,00 & $1.151,36$ & $3.609,19$ & 492,77 & $1.106,77$ & 0,00 & 600,96 & $25.866,08$ & $2.624,79$ & $22.251,13$ & $60.639,02$ \\
\hline nov-15 & $3.027,72$ & 0,00 & $1.367,24$ & $3.212,97$ & 460,82 & $1.080,16$ & 0,00 & 538,63 & $24.264,06$ & $2.554,00$ & $21.133,69$ & $57.639,29$ \\
\hline dez-15 & $3.027,72$ & 0,00 & $1.367,24$ & $3.230,87$ & 430,46 & $1.080,16$ & 0,00 & 538,36 & $26.676,31$ & $2.850,91$ & $21.738,58$ & $60.940,61$ \\
\hline jan-16 & $2.828,93$ & 0,00 & 899,50 & $3.296,91$ & 493,00 & $1.000,35$ & 0,00 & 350,56 & $24.724,16$ & $2.678,32$ & $20.010,11$ & $56.281,84$ \\
\hline fev-16 & $3.027,72$ & 0,00 & $1.367,24$ & $3.370,36$ & 436,03 & $1.096,13$ & 0,00 & 575,92 & $24.901,14$ & $2.217,28$ & $19.120,86$ & $56.112,68$ \\
\hline SOMAS & $35.323,38$ & & $14.032,20$ & $40.363,99$ & $5.699,68$ & $12.626,74$ & & $5.671,83$ & $303.141,81$ & $31.307,86$ & $261.808,19$ & $709.975,68$ \\
\hline
\end{tabular}

ISSN 1679-8902 
APÊNDICE B

LEVANTAMENTO DO ÍNDICE 'PREÇO MÉDIO' 


\begin{tabular}{|c|c|c|c|}
\hline AGOSTO 2016 & & & \\
\hline INSTALAÇÃO & $\begin{array}{l}\text { Total } \\
\text { (kWh) }\end{array}$ & $\begin{array}{l}\text { Total } \\
\text { (RS) }\end{array}$ & $\begin{array}{c}\text { Preço } \\
\text { Médio (R\$) }\end{array}$ \\
\hline ADMINISTRATIVO & 1.052 & 599 & \\
\hline 3060001674 & 1.052 & 599 & 0,57 \\
\hline SISTEMA DE ABASTECIMENTO & 32.710 & $\overline{16.629}$ & \\
\hline 3060015844 & 7.430 & 3.741 & 0,50 \\
\hline 3060002674 & 2.478 & 1.248 & 0,50 \\
\hline 3060011563 & 6.786 & 3.417 & 0,50 \\
\hline 3060000945 & 1.383 & 696 & 0,50 \\
\hline 3060001797 & 2.103 & 1.059 & 0,50 \\
\hline 3060010122 & 3.903 & 2.223 & 0,57 \\
\hline 3060001082 & 287 & 145 & 0,50 \\
\hline 3060000167 & 3.433 & 1.729 & 0,50 \\
\hline 3060001774 & 110 & 55 & 0,50 \\
\hline 3060000184 & 904 & 515 & 0,57 \\
\hline 3060003016 & 50 & 25 & 0,50 \\
\hline 3060017892 & 21.509 & 10.830 & 0,50 \\
\hline 3060000077 & 50 & 25 & 0,50 \\
\hline 3060017491 & 437 & 220 & 0,50 \\
\hline 3060002403 & 4.695 & 2.364 & 0,50 \\
\hline 3060012234 & 5.788 & 2.914 & 0,50 \\
\hline 3060003332 & 434 & 219 & 0,50 \\
\hline 3060011592 & 3.639 & 1.832 & 0,50 \\
\hline SISTEMA DE ESGOTO & 15.181 & 7.734 & \\
\hline 4001443349 & 100 & 50 & 0,50 \\
\hline 3060002059 & 100 & 50 & 0,50 \\
\hline 3060011045 & 510 & 257 & 0,50 \\
\hline 3060011058 & 100 & 50 & 0,50 \\
\hline 3060011102 & 100 & 50 & 0,50 \\
\hline 3060010127 & 100 & 50 & 0,50 \\
\hline 3060010179 & 188 & 95 & 0,50 \\
\hline 3060010223 & 100 & 50 & 0,50 \\
\hline 3060003333 & 100 & 50 & 0,50 \\
\hline 3060017367 & 509 & 256 & 0,50 \\
\hline 3060014810 & 3.215 & 1.619 & 0,50 \\
\hline 3060010561 & 2.940 & 1.480 & 0,50 \\
\hline 4001174548 & 185 & 93 & 0,50 \\
\hline 4001201448 & 2.729 & 1.374 & 0,50 \\
\hline 3060008824 & 768 & 387 & 0,50 \\
\hline 3060008851 & 100 & 50 & 0,50 \\
\hline 3060008867 & 100 & 50 & 0,50 \\
\hline 4001195220 & 3.151 & 1.587 & 0,50 \\
\hline 3060009742 & 1.812 & 912 & 0,50 \\
\hline 4000785238 & 1.472 & 839 & 0,57 \\
\hline 3060001434 & 552 & 278 & 0,50 \\
\hline 3060001262 & 1.260 & 718 & 0,57 \\
\hline 3060010287 & 10.170 & 5.121 & 0,50 \\
\hline
\end{tabular}


Luciana Carla Ferreira de Souza

Lucarla24@gmail.com

Possui graduação em TECNOLOGIA EM SANEAMENTO pela Universidade Estadual de Campinas (1996), ESPECIALIZAÇÃO EM ENGENHARIA

AMBIENTAL pela Universidade Estadual de Campinas (2001), MESTRADO em Engenharia Civil pela Universidade Estadual de Campinas (2004) e DOUTORADO em Engenharia Civil pela Universidade Estadual de Campinas (2013). Atualmente é membro - Câmara Técnica de Monitoramento Hidrológico, membro - Câmara Técnica de Saneamento - Comitê PCJ, membro - Câmara Técnica de Água Subterrânea - Comitê PCJ, membro - Câmara Técnica de PLano de Bacia - Comitê PCJ, professor da Faculdade de Jaguariúna, membro - Câmara Técnica de Outorgas e Licenças - Comitê PCJ, membro do Conselho do Fundo Municipal de Habitação, membro do Conselho Municipal de Defesa do Meio Ambiente - COMDEMA, diretora administrativa da Prefeitura do Município de Jaguariúna e membro do Conselho Municipal do Plano Diretor. Tem experiência na área de Engenharia Sanitária, com ênfase em Planejamento Integrado dos Recursos Hídricos, atuando principalmente nos seguintes temas: tratamento do solo; efluente de indústria cítrica, água subterrânea, efluentes industriais, água subterrânea e água superficial.

Lucas Henrique Rodrigues Dorta Ihrdorta@gmail.com

Está cursando Engenharia Ambiental e Sanitária na Pontifícia Universidade Católica de Campinas com bolsa integral PROUNI. Atualmente é estagiário Departamento de Água e Esgoto do município de Jaguariúna. 